\title{
Bivalirudin or unfractionated heparin in patients with acute coronary syndromes managed invasively with and without ST elevation (MATRIX): randomised controlled trial
}

\begin{abstract}
Sergio Leonardi,, ${ }^{1}$ Enrico Frigoli, ${ }^{2}$ Martina Rothenbühler, 3,4 Eliano Navarese, ${ }^{5}$ Paolo Calabró, ${ }^{6}$ Paolo Bellotti, ${ }^{7}$ Carlo Briguori, ${ }^{8}$ Marco Ferlini, ${ }^{1}$ Bernardo Cortese, ${ }^{9}$ Alessandro Lupi, ${ }^{10}$ Salvatore Lerna, ${ }^{11}$ Dennis Zavallonito-Parenti, ${ }^{12}$ Giovanni Esposito, ${ }^{13}$ Simone Tresoldi, ${ }^{14}$ Antonio Zingarelli, ${ }^{15}$ Stefano Rigattieri, ${ }^{16}$ Cataldo Palmieri, ${ }^{17}$ Armando Liso, ${ }^{18}$ Fabio Abate, ${ }^{19}$ Marco Zimarino, ${ }^{20}$ Marco Comeglio, ${ }^{21}$ Gabriele Gabrielli,,22 Alaide Chieffo, ${ }^{23}$ Salvatore Brugaletta, ${ }^{24}$ Ciro Mauro, ${ }^{25}$ Nicolas M Van Mieghem, ${ }^{26}$ Dik Heg,, 3 Peter Jüni, ${ }^{37}$ Stephan Windecker, ${ }^{28}$ Marco Valgimigli28 for the MATRIX Investigators
\end{abstract}

For numbered affiliations see end of article.

Correspondence to: M Valgimigli marco.valgimigli@insel.ch online only. To view please visit the journal online.

Cite this as: BMJ 2016;354:i4935 http://dx.doi.org/10.1136/bmj.i4935

Accepted: 2 September 2016
Additional material is published

\section{ABSTRACT}

OBJECTIVE

To test the optimal antithrombotic regimen in patients with acute coronary syndrome.

DESIGN

andomised controlled trial.

SETTING

Patients with acute coronary syndrome with and without ST segment elevation in 78 centres in Italy, the Netherlands, Spain, and Sweden.

\begin{abstract}
PARTICIPANTS
7213 patients with acute coronary syndrome and planned percutaneous coronary intervention: 4010 with ST segment elevation and 3203 without ST segment elevation. The primary study results in the overall population have been reported previously.

INTERVENTIONS

Patients were randomly assigned, in an open label fashion, to one of two regimens: bivalirudin with glycoprotein Ilb/IIla inhibitors restricted to procedural complications or heparin with or without glycoprotein Ilb/Illa inhibitors.

\section{MAIN OUTCOME MEASURES}

Primary endpoints were the occurrence of major adverse cardiovascular events, defined as death, myocardial infarction or stroke; and net adverse clinical events, defined as major bleeding or major adverse cardiovascular events, both assessed at 30 days. Analyses were performed by the principle of intention to treat.
\end{abstract}

\section{WHAT IS ALREADY KNOWN ON THIS TOPIC}

The optimal antithrombotic regimen in patients with acute coronary syndrome with and without ST segment elevation is not yet defined

\section{WHAT THIS STUDY ADDS}

A regimen of bivalirudin alone compared with unfractionated heparin with provisional use of glycoprotein Ilb/IIla inhibitors in patients with acute coronary syndrome with or without ST segment elevation, did not result in reduced major adverse cardiovascular events or net adverse clinical events

\section{RESULTS}

Use of a glycoprotein IIb/IIla inhibitor in patients assigned to heparin was planned at baseline in $30.7 \%$ of patients with ST segment elevation, in $10.9 \%$ without ST segment elevation, and in no patients assigned to bivalirudin. In patients with ST segment elevation, major adverse cardiovascular events occurred in 118 (5.9\%) assigned to bivalirudin and 129 (6.5\%) assigned to heparin (rate ratio 0.90, 95\% confidence interval 0.70 to $1.16 ; \mathrm{P}=0.43$ ), whereas net adverse clinical events occurred in 139 (7.0\%) patients assigned to bivalirudin and $163(8.2 \%)$ assigned to heparin $(0.84,0.67$ to $1.05 ; \mathrm{P}=0.13)$. In patients without ST segment elevation, major adverse cardiovascular events occurred in 253 (15.9\%) assigned to bivalirudin and $262(16.4 \%)$ assigned to heparin $(0.97,0.80$ to $1.17 ; \mathrm{P}=0.74)$, whereas net adverse clinical events occurred in 262 (16.5\%) patients assigned to bivalirudin and 281 (17.6\%) assigned to heparin $(0.93,0.77$ to $1.12 ; \mathrm{P}=0.43)$.

\section{CONCLUSIONS}

A bivalirudin monotherapy strategy compared with heparin with or without glycoprotein Ilb/IIla inhibitors, did not result in reduced major adverse cardiovascular events or net adverse clinical events in patients with or without ST segment elevation.

TRIAL REGISTRATION

ClinicalTrials.gov NCT01433627.

\section{Introduction}

In patients with acute coronary syndromes managed invasively with coronary angiography and revascularisation the optimal strategy for preventing coronary thrombosis and ischaemia, while limiting bleeding, is uncertain. Two commonly adopted regimens consist of unfractionated heparin, an indirect thrombin inhibitor, with or without concomitant use of a glycoprotein IIb/ IIIa inhibitor in case of percutaneous coronary intervention; and bivalirudin, a direct thrombin inhibitor, with the use of glycoprotein IIb/IIIa inhibitors restricted to periprocedural thrombotic complications. This latter strategy has been associated with reduced bleeding, an outcome extensively associated with mortality. Previous moderately sized studies in patients with acute coronary syndrome provided conflicting results on the 
comparative efficacy and safety of these two strategies. $^{1-4}$ We therefore designed the Minimizing Adverse Haemorrhagic Events by Transradial Access Site and Systemic Implementation of Angiox (MATRIX) phase 3 programme in patients with acute coronary syndrome managed invasively via the radial or femoral route. ${ }^{5}$ In this large, randomised controlled trial we assessed whether bivalirudin is superior to unfractionated heparin with or without concomitant use of glycoprotein IIb/IIIa inhibitors. Bivalirudin did not significantly reduce the two coprimary endpoints of major adverse cardiovascular events and net adverse clinical events in the overall acute coronary syndrome population of 7213 patients. ${ }^{6}$

However, the use of these two strategies in clinical practice, ${ }^{7}$ as well as the profile of efficacy on ischaemic and thrombotic complications (eg, stent thrombosis), and safety in terms of bleeding ${ }^{8}$ might differ depending on the type of acute coronary syndrome at presentationthat is, with or without persistent ST segment elevation.

We present the results of prespecified, randomised comparisons of bivalirudin with heparin in two MATRIX subpopulations with acute coronary syndrome: 4010 patients presenting with persistent ST elevation and 3203 patients presenting without persistent ST segment elevation for whom percutaneous coronary intervention was planned at the time of coronary angiography.

\section{Methods}

Study design

MATRIX was a programme of three independent randomised controlled trials in an all comers population with acute coronary syndrome, with or without persistent ST segment elevation. The first trial, MATRIX Access Site, compared transradial access with transfemoral access in 8404 patients with acute coronary syndrome, 4010 (47.7\%) with ST segment elevation and 4394 (52.3\%) without ST segment elevation. ${ }^{9}$ The second trial, MATRIX Antithrombin, was a randomised comparison of two antithrombotic strategies: bivalirudin with use of glycoprotein IIb/IIIa inhibitors restricted to angiographic complications (eg, giant thrombus) compared with unfractionated heparin with use of glycoprotein IIb/IIIa inhibitors left to the discretion of the investigator. ${ }^{6}$ These strategies were compared in the overall population with ST segment elevation $(n=4010)$ and in patients without ST segment elevation for whom percutaneous coronary intervention was planned $(\mathrm{n}=3203,72.9 \%$ of the overall population without ST segment elevation). The third trial, MATRIX Treatment Duration, was a randomised comparison within patients assigned to bivalirudin, comparing extended bivalirudin administration after percutaneous coronary intervention with short term administration during percutaneous coronary intervention only. ${ }^{6}$

\section{Participants}

Patients with ST segment elevation were eligible: 1 ) if they experienced more than 20 minutes of ischaemic symptoms with ST segment elevation of $\geq 1 \mathrm{~mm}$ in two or more contiguous electrocardiogram leads, or with a new left bundle branch block, or 2) in case of ST segment depression of $\geq 1 \mathrm{~mm}$ in two or more of leads V1-V3 with a positive terminal $\mathrm{T}$ wave if presented within 12 hours of symptom onset, or 3) if there was evidence of continuing ischaemia or previous fibrinolytic treatment between 12 and 24 hours after symptom onset. We use the term acute coronary syndrome with ST segment elevation instead of ST elevation myocardial infarction to recognise the possibility of an aborted myocardial infarction in patients presenting with acute coronary syndrome and persistent ST segment elevation. ${ }^{10}$

Patients without ST segment elevation were eligible if they had a history consistent with new or worsening cardiac ischaemia, occurring at rest or with minimal activity within seven days before randomisation, and fulfilled at least two high risk criteria among the following: age 60 years or older, increase in cardiac biomarkers, or electrocardiographic changes consistent with cardiac ischaemia; consideration as a possible candidate for percutaneous coronary intervention after completion of coronary angiography.

Key exclusion criteria (for patients both with and without ST segment elevation) were treatment with low molecular weight heparins within the past six hours; treatment with any glycoprotein IIb/IIIa inhibitor in the previous three days; contraindications to angiography, including but not limited to severe peripheral vascular disease; and presumed life expectancy of less than 30 days. Detailed inclusion and exclusion criteria have been published elsewhere and are listed in the appendix. ${ }^{12}$ All patients gave written informed consent.

\section{Randomisation}

Using a computer generated random sequence, we randomised patients in a 1:1 ratio to receive the bivalirudin strategy or unfractionated heparin strategy, with a random block size stratified by type of acute coronary syndrome-ie, with ST segment elevation versus without ST segment elevation-intended or ongoing use of $\mathrm{P}_{12}$ inhibitor (clopidogrel versus ticagrelor or prasugrel), and study site.

Owing to the high likelihood of patients with ST segment elevation receiving percutaneous coronary intervention, we simultaneously randomised all patients with ST segment elevation to the comparisons of access site, antithrombin, and treatment duration (one step randomisation process). To account for the patients without ST segment elevation who would not undergo percutaneous coronary intervention after angiography and to minimise the risk that this might unbalance the distribution of patients for the tested drug options, we also allowed randomisation to the antithrombin comparison (either bivalirudin or heparin strategy) after coronary angiography and the decision had been taken to proceed to percutaneous coronary intervention. Hence, a two step randomisation process (randomisation to access site before angiography followed by randomisation to antithrombin, including randomisation to treatment duration, only in those undergoing percutaneous coronary intervention) was selected in most of the patients without ST segment elevation. Additionally, 
randomisation of patients without ST segment elevation for which a two step randomisation was selected by the investigator was stratified by the actual treatment strategy (ie, coronary angiography only, not followed by percutaneous coronary intervention; or coronary angiography followed by planned percutaneous coronary intervention).

\section{Procedures}

We administered all interventions in an open label fashion. Bivalirudin was given according to the product labelling, with a bolus of $0.75 \mathrm{mg} / \mathrm{kg}$ body weight followed immediately by an infusion of $1.75 \mathrm{mg} / \mathrm{kg}$ body weight hourly until completion of percutaneous coronary intervention. Bivalirudin was then stopped at the end of percutaneous coronary intervention, or prolonged in accordance with the subsequent random assignment. In patients allocated to prolonged treatment, bivalirudin could be administered for up to four hours at the full dose or at a reduced dose of $0.25 / \mathrm{mg} / \mathrm{kg}$ body weight hourly for at least six hours, at the discretion of the treating doctors. Heparin was dosed at 70-100 units/kg body weight in patients not receiving glycoprotein IIb/IIIa inhibitors and at 50-70 units/kg body weight in patients receiving glycoprotein IIb/IIIa inhibitors. Subsequent heparin dosing based on activated clotting time was again left to the discretion of the investigator. A glycoprotein IIb/IIIa inhibitor could be administered before percutaneous coronary intervention in patients in the heparin group based on investigator's judgment, but in the bivalirudin group it was restricted only to patients with thrombotic complications at the time of percutaneous coronary intervention, including no reflow or giant thrombus. Use of other drugs was allowed as per guidelines. Clinical follow-up was performed at 30 days.

\section{Outcomes}

The MATRIX Antithrombin trial had two coprimary outcomes, identical for patients with and without ST segment elevation: major adverse cardiovascular events and net adverse clinical events, both assessed at 30 days. Considering the extensive association of bleeding with mortality and that both experimental treatments tested in MATRIX (radial access and bivalirudin monotherapy) were expected to reduce bleeding, we included net adverse clinical events as the coprimary endpoint.

We defined major adverse cardiovascular events as the composite of all cause mortality, myocardial infarction, or stroke; and net adverse clinical events as the composite of major bleeding unrelated to coronary artery bypass graft (Bleeding Academic Research Consortium type 3 or 5 , also see supplementary file), ${ }^{11}$ or major adverse cardiovascular events. Secondary outcomes included each component of the composite outcomes, cardiovascular mortality, and stent thrombosis. Bleeding was also assessed and adjudicated on the basis of the Thrombolysis In Myocardial Infarction (TIMI) and Global Utilization of Streptokinase and Tissue Plasminogen Activator for Occluded Coronary Arteries (GUSTO) scales. ${ }^{12}$
An independent clinical events committee, blinded to randomised treatment allocation, adjudicated all suspected events according to prespecified definitions. The appendix details the definitions for endpoints adjudicated by the clinical events committee.

\section{Statistical analysis}

The overall MATRIX Antithrombin trial was designed as a superiority study on two coprimary outcomes: major adverse cardiovascular events and net adverse clinical events. We expected that the incidence of 30 day major adverse cardiovascular events (death, myocardial infarction, or stroke) on an intention to treat basis to be $4.2 \%$ in the bivalirudin group and $6.0 \%$ in the unfractionated heparin group (relative risk 0.70). With an $\alpha$ error set at $2.5 \%$ to correct for the two coprimary endpoints, we considered that a sample size of 6800 randomised patients or 3400 patients in each group would provide $85 \%$ power. For 30 day net adverse clinical events (death, myocardial infarction, stroke, or major bleeding), we expected an incidence on an intention to treat basis of $6.3 \%$ in the bivalirudin group and $9.0 \%$ in the unfractionated heparin group (relative risk 0.70). We determined that we would need 6800 randomised patients or 3400 patients in each group to provide $95 \%$ power with an $\alpha$ error set at $2.5 \%$ to correct for the two coprimary endpoints. Otherwise, we made no adjustments for multiple comparisons when analysing secondary endpoints. We analysed the data according to the intention to treat principle. Outcomes were assessed separately for patients with and without ST segment elevation as time to first event using the Mantel-Cox method to estimate unadjusted rate ratios and corresponding 95\% confidence intervals. ${ }^{13}$ The proportional hazard assumption was verified on the basis of Schoenfeld residuals. We used a two sided log-rank test, and survival curves were constructed using Kaplan-Meier estimates. We performed stratified analyses according to prespecified subgroups (centre's annual volume of percutaneous coronary intervention, age, sex, body mass index, intended start or continuation of prasugrel or ticagrelor, diabetes, estimated glomerular filtration rate, history of peripheral vascular disease, previous heparin, and randomisation to access site) and estimated possible effect modifications using interaction terms or tests for trend across ordered groups. We chose not to adjust for centre because the number of observations in each centre varies substantially (range 1-794). However, to account for the within group correlation, we applied a shared frailty model using Cox regression and observed that hazard ratios were similar to our original Cox regression models where we did not use a shared frailty model. All analyses were performed using the statistical packages Stata 14.1 and R 3.3.0.

\section{Patient involvement}

No patients were involved in setting the research question or the outcome measures, nor were they involved in developing plans for recruitment, design, or implementation of the study. No patients were asked to advise on interpretation or writing up of results. We plan to 


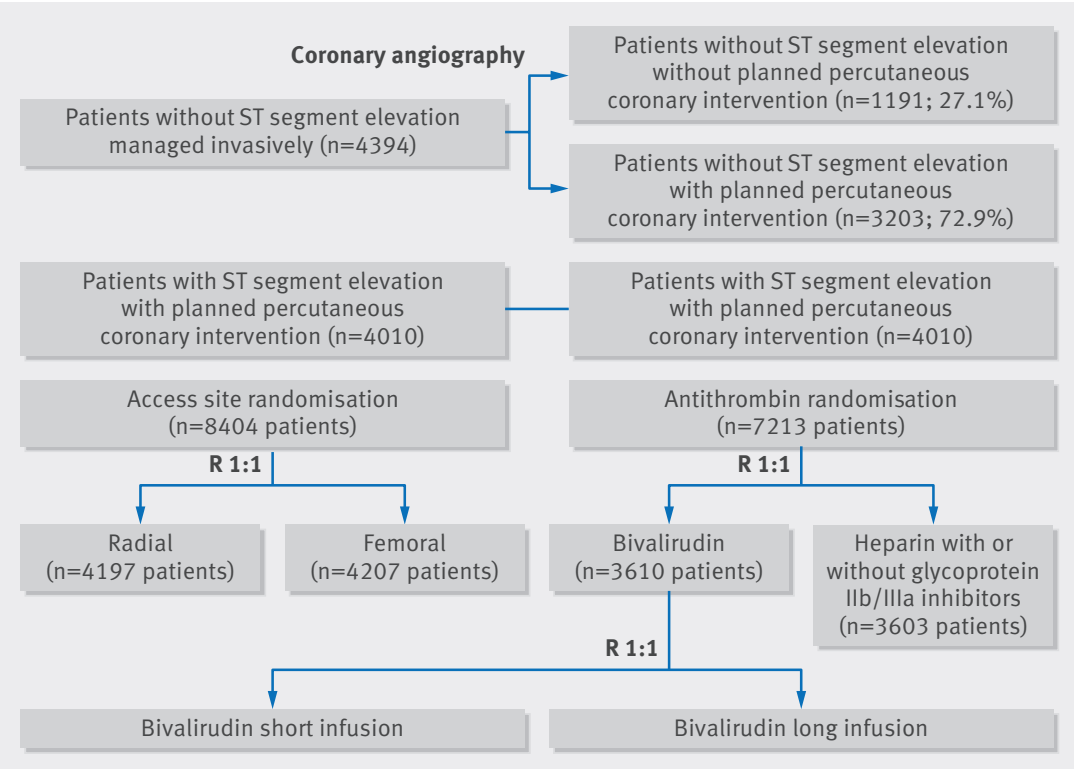

Fig 1 | Flow of study participants

Table 1 | Baseline characteristics of participants with acute coronary syndrome with and without ST segment elevation. Values are numbers (percentages) unless stated otherwise

\begin{tabular}{|c|c|c|c|c|}
\hline \multirow[b]{2}{*}{ Characteristics } & \multicolumn{2}{|c|}{ With ST segment elevation } & \multicolumn{2}{|c|}{ Without ST segment elevation } \\
\hline & $\begin{array}{l}\text { Bivalirudin } \\
(n=2012)\end{array}$ & $\begin{array}{l}\text { Unfractionated } \\
\text { heparin }(n=1998)\end{array}$ & $\begin{array}{l}\text { Bivalirudin } \\
(n=1598)\end{array}$ & $\begin{array}{l}\text { Unfractionated } \\
\text { heparin }(n=1605)\end{array}$ \\
\hline Mean (SD) age (years) & $63.9(12.2)$ & $63.9(12.0)$ & $67.4(11.2)$ & $67.3(11.4)$ \\
\hline Age $\geq 75$ years & $445(22.1)$ & $423(21.2)$ & $461(28.8)$ & $481(30.0)$ \\
\hline Male sex & $1549(77.0)$ & $1544(77.3)$ & $1182(74.0)$ & $1220(76.0)$ \\
\hline Mean (SD) weight $(\mathrm{kg})$ & $77.8(13.5)$ & $77.4(14.0)$ & $77.7(14.0)$ & $77.4(13.7)$ \\
\hline Mean (SD) body mass index & $27.1(4.1)$ & $26.9(4.1)$ & $27.3(4.3)$ & $27.2(4.1)$ \\
\hline Diabetes mellitus & $363(18.0)$ & $355(17.8)$ & $452(28.3)$ & $431(26.9)$ \\
\hline Insulin dependent & $73(3.6)$ & $79(4.0)$ & $123(7.7)$ & $108(6.7)$ \\
\hline Current smoker & $820(40.8)$ & $815(40.8)$ & $487(30.5)$ & $487(30.3)$ \\
\hline Hypercholesterolaemia & $783(38.9)$ & $785(39.3)$ & $813(50.9)$ & $773(48.2)$ \\
\hline Hypertension & $1150(57.2)$ & $1084(54.3)$ & $1114(69.7)$ & $1138(70.9)$ \\
\hline Family history of CAD & $561(27.9)$ & $563(28.2)$ & $430(26.9)$ & $429(26.7)$ \\
\hline Previous MI & $188(9.3)$ & $196(9.8)$ & $342(21.4)$ & $305(19.0)$ \\
\hline Previous $\mathrm{PCl}$ & $200(9.9)$ & $186(9.3)$ & $336(21.0)$ & $318(19.8)$ \\
\hline Previous CABG & $29(1.4)$ & $23(1.2)$ & $98(6.1)$ & $72(4.5)$ \\
\hline Previous TIA or stroke & $88(4.4)$ & $84(4.2)$ & $93(5.8)$ & $101(6.3)$ \\
\hline Peripheral vascular disease & $106(5.3)$ & $123(6.2)$ & $190(11.9)$ & $161(10.0)$ \\
\hline COPD & $100(5.0)$ & $85(4.3)$ & $116(7.3)$ & $135(8.4)$ \\
\hline History of renal failure & $21(1.0)$ & $24(1.2)$ & $27(1.7)$ & $23(1.4)$ \\
\hline Dialysis & $3(0.1)$ & $0(0.0)$ & $2(0.1)$ & $2(0.1)$ \\
\hline \multicolumn{5}{|l|}{ Clinical presentation } \\
\hline Cardiac arrest & $67(3.3)$ & $72(3.6)$ & $13(0.8)$ & $11(0.7)$ \\
\hline \multicolumn{5}{|l|}{ Killip class: } \\
\hline I & $1814(90.2)$ & $1778(89.0)$ & $1461(91.4)$ & $1462(91.1)$ \\
\hline II & $129(6.4)$ & $157(7.9)$ & $95(5.9)$ & $107(6.7)$ \\
\hline III & $38(1.9)$ & $29(1.5)$ & $38(2.4)$ & $35(2.2)$ \\
\hline IV & $31(1.5)$ & $34(1.7)$ & $4(0.3)$ & $1(0.1)$ \\
\hline Previous lytic treatment & $96(4.8)$ & $101(5.1)$ & $1(0.1)$ & $0(0.0)$ \\
\hline Mean (SD) SBP (mm Hg) & $136.2(26.8)$ & $136.0(27.1)$ & $141.5(24.6)$ & $140.9(24.0)$ \\
\hline Mean (SD) heart rate (beats/min) & $77.0(17.3)$ & $77.1(17.2)$ & $75.2(16.3)$ & $74.1(15.3)$ \\
\hline Mean (SD) LVEF (\%) & $48.7(9.5)$ & $49.1(9.5)$ & $52.8(9.1)$ & $53.2(9.1)$ \\
\hline Mean (SD) eGFR (mL/min) & $84.4(25.5)$ & $85.2(25.8)$ & $82.6(24.5)$ & $83.4(25.6)$ \\
\hline eGFR $<60$ & $307(15.4)$ & $301(15.3)$ & $282(17.7)$ & $287(17.9)$ \\
\hline eGFR<30 & $20(1.0)$ & $25(1.3)$ & $18(1.1)$ & $15(0.9)$ \\
\hline
\end{tabular}

$C A D=$ coronary artery disease; $\mathrm{Ml}=$ myocardial infarction; $\mathrm{PCl}=$ percutaneous coronary intervention; $\mathrm{CABG}=$ coronary artery bypass graft; $T \mid A=$ transient ischaemic attack; $C O P D=$ chronic obstructive pulmonary disease; $S B P=$ systolic blood pressure; LVEF=left ventricular ejection fraction; eGFR=estimated glomerular filtration rate. disseminate the results of the research to all the scientific community, including study participants.

\section{Results}

\section{Patients}

Between 11 October 2011 and 7 November 2014 a total of 7213 patients were randomised in the MATRIX Antithrombin trial in 78 centres in Italy, the Netherlands, Spain, and Sweden. Of these, 4010 (56\%) qualified for acute coronary syndrome with ST segment elevation at presentation (randomised after a median of 3.1 hours from symptom onset) and 3203 (44\%) for acute coronary syndrome without ST segment elevation (randomised after a median of 36.4 hours from symptom onset, fig 1 ). Of the 4010 patients with ST segment elevation, an investigator reported primary percutaneous coronary intervention as the indication for angiography in 3647-that is, $91 \%$. Of the remaining 363 patients with ST segment elevation (9.0\%), 190 did not receive percutaneous coronary intervention and 173 had percutaneous coronary intervention for an indication different from primary percutaneous coronary intervention. Overall, 3442 patients (95.3\%) in the bivalirudin group and 3474 (96.4\%) in the heparin group actually received the allocated treatment. At 30 days, complete follow-up information was available for 7198 (99.8\%) patients (see supplementary figures S1 and S2). Baseline characteristics were similar within qualifying groups with acute coronary syndrome, with burden of risk factors for atherothrombosis and comorbidities (including hypertension, diabetes, hypercholesterolaemia, previous myocardial infarction) higher in patients who qualified for the group without ST segment elevation than those who qualified for the group with ST segment elevation (table 1). Use of a glycoprotein IIb/IIIa inhibitor in patients assigned to heparin was planned at the time of randomisation in $30.7 \%$ of patients with ST segment elevation and $10.9 \%$ without ST segment elevation. In accordance with the protocol, no patient was assigned to bivalirudin for whom a glycoprotein IIb/IIIa inhibitor was planned at the time of randomisation (see supplementary appendix). Bailout use of a glycoprotein IIb/IIIa inhibitor was not significantly different between randomised groups in patients without ST segment elevation and higher in the bivalirudin group (6.0\%) compared with heparin $(4.3 \%)$ in the population with ST segment elevation $(\mathrm{P}=0.014)$. Administration of an oral $\mathrm{P}_{2} \mathrm{Y}_{12}$ inhibitor (clopidogrel, ticagrelor, or prasugrel) before coronary angiography was similar between patients in the bivalirudin group and heparin group, in the populations both with and without ST segment elevation (see supplementary table S1). The appendix lists the other procedural characteristics.

\section{Clinical outcomes}

In patients with ST segment elevation, major adverse cardiovascular events occurred in 118 (5.9\%) assigned to bivalirudin and $129(6.5 \%)$ assigned to heparin (rate ratio $0.90,95 \%$ confidence interval 0.70 to $1.16, \mathrm{P}=0.43$ ), whereas net adverse clinical events occurred in 139 (7.0\%) assigned to bivalirudin and 163 (8.2\%) assigned to heparin (0.84, 0.67 to $1.05, \mathrm{P}=0.13$, fig 2 and table 2 ). 

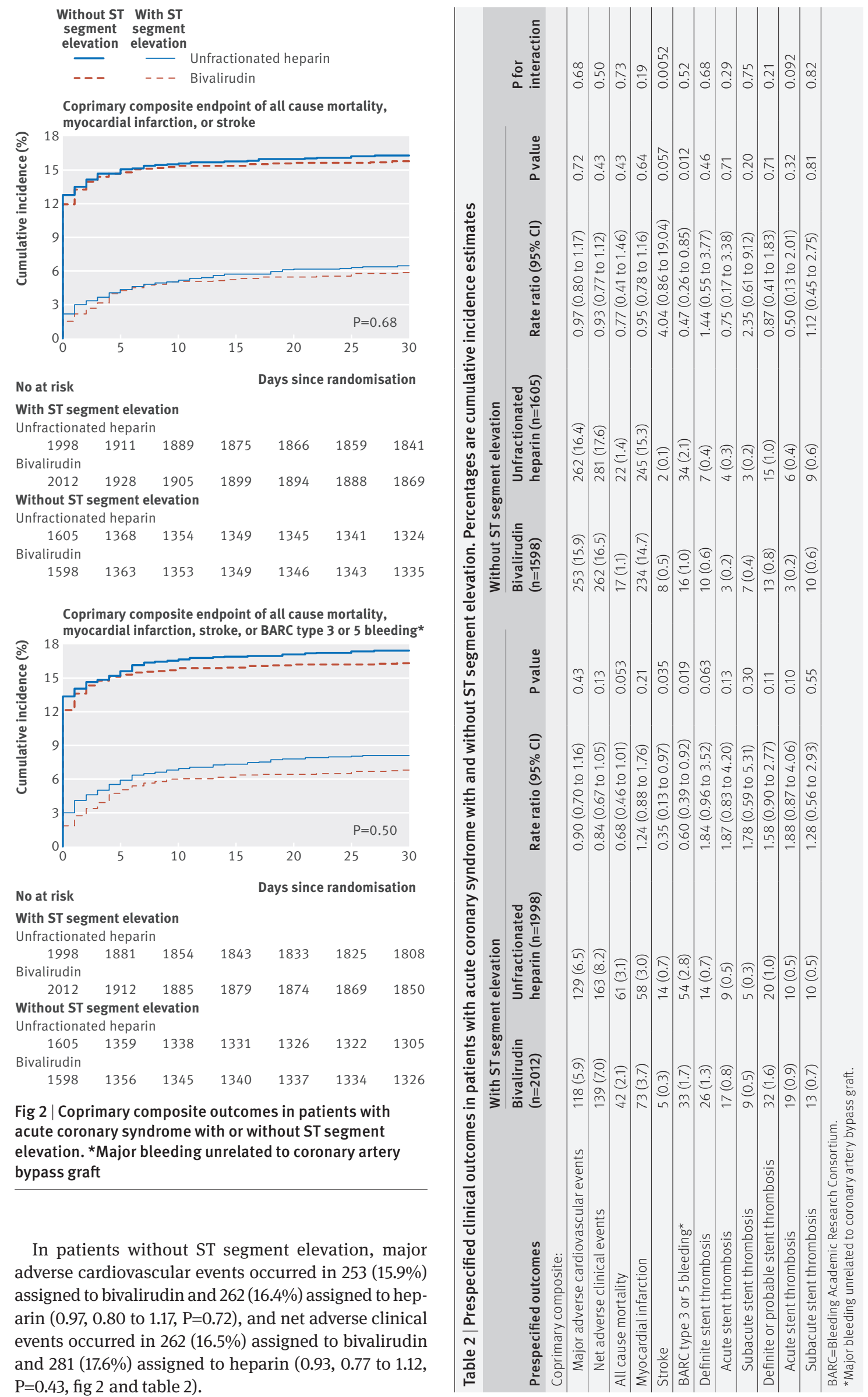

In patients without ST segment elevation, major adverse cardiovascular events occurred in 253 (15.9\%) assigned to bivalirudin and $262(16.4 \%)$ assigned to heparin (0.97, 0.80 to $1.17, \mathrm{P}=0.72)$, and net adverse clinical events occurred in $262(16.5 \%)$ assigned to bivalirudin and $281(17.6 \%)$ assigned to heparin $(0.93,0.77$ to 1.12 , $\mathrm{P}=0.43$, fig 2 and table 2). 
Without ST With ST

segment segment

elevation elevation

$-\quad-\quad--$ Unfractionated heparin

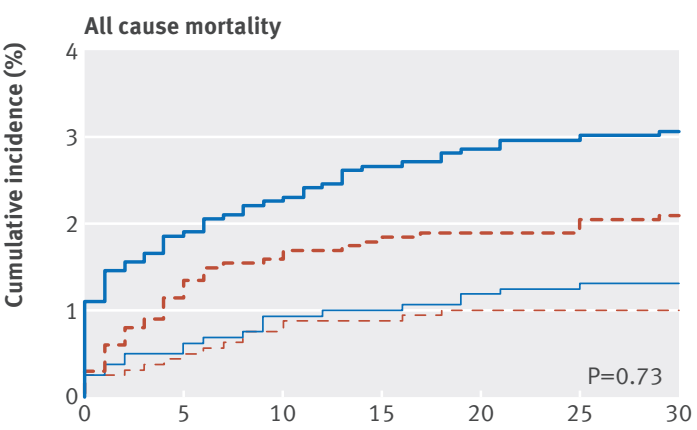

No at risk

Days since randomisation

With ST segment elevation

Unfractionated heparin

$\begin{array}{rrrrrrr}1998 & 1955 & 1945 & 1936 & 1931 & 1924 & 1907 \\ \begin{array}{c}\text { Bivalirudin } \\ 2012\end{array} & 1985 & 1973 & 1967 & 1965 & 1961 & 1944 \\ \text { Without ST segment elevation } & & & & \\ \text { Unfractionated heparin } \\ \begin{array}{r}1605 \\ 1695\end{array} & 1588 & 1586 & 1582 & 1578 & 1561 \\ \text { Bivalirudin } \\ 1598 & 1590 & 1584 & 1581 & 1579 & 1575 & 1567\end{array}$

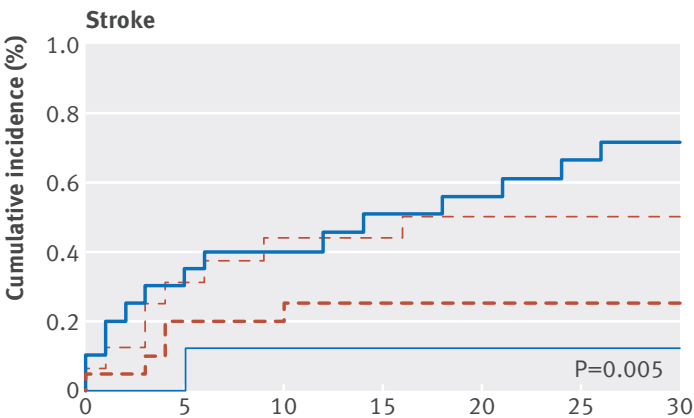

Days since randomisation

No at risk

With ST segment elevation

Unfractionated heparin

\begin{tabular}{|c|c|c|c|c|c|c|}
\hline 1998 & 1949 & 1937 & 1927 & 1921 & 1914 & 1896 \\
\hline \multicolumn{7}{|l|}{ Bivalirudin } \\
\hline 2012 & 1981 & 1969 & 1964 & 1962 & 1958 & 1941 \\
\hline \multicolumn{7}{|c|}{$\begin{array}{l}\text { Without ST segment elevation } \\
\text { Unfractionated heparin }\end{array}$} \\
\hline 1605 & 1595 & 1586 & 1584 & 1580 & 1576 & 1560 \\
\hline alirud & & & & & & \\
\hline & & & & & 69 & \\
\hline
\end{tabular}

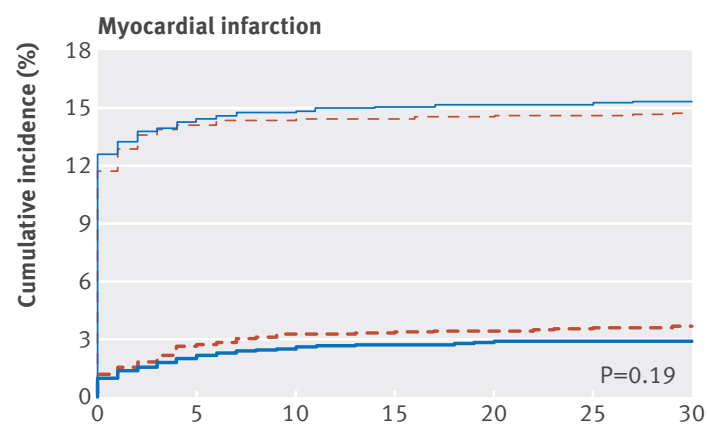

No at risk

Days since randomisation

With ST segment elevation

Unfractionated heparin

\begin{tabular}{|c|c|c|c|c|c|c|}
\hline 1998 & 1916 & 1896 & 1883 & 1875 & 1868 & 1851 \\
\hline alirudin & & & & & & \\
\hline 2012 & 1932 & 1909 & 1902 & 1897 & 1891 & 1872 \\
\hline $\begin{array}{l}\text { nout S1 } \\
\text { action }\end{array}$ & gment & evation & & & & \\
\hline $\begin{array}{r}1605 \\
\text { alirudin }\end{array}$ & 1368 & 1355 & 1350 & 1346 & 1342 & 1325 \\
\hline 1598 & 1368 & 1359 & 1355 & 1352 & 1349 & 13 \\
\hline
\end{tabular}

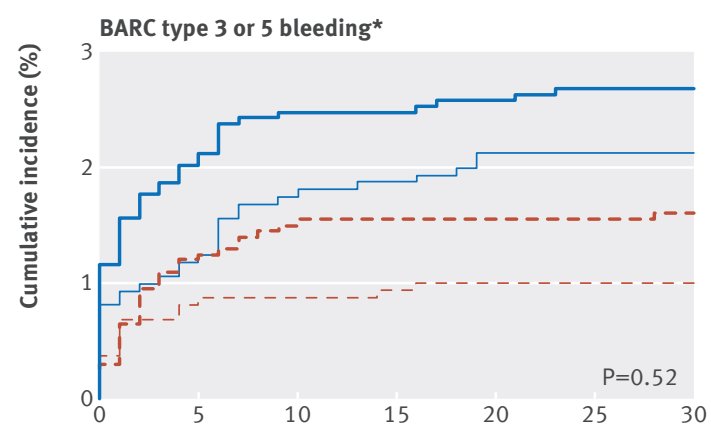

No at risk

Days since randomisation

With ST segment elevation

Unfractionated heparin

$\begin{array}{lllllll}1998 & 1922 & 1906 & 1901 & 1894 & 1886 & 1870\end{array}$

Bivalirudin

$\begin{array}{lllllll}2012 & 1965 & 1947 & 1941 & 1939 & 1935 & 1918\end{array}$

Without ST segment elevation

Unfractionated heparin

$\begin{array}{lllllll}1605 & 1580 & 1565 & 1561 & 1555 & 1551 & 1534\end{array}$

Bivalirudin

$\begin{array}{lllllll}1598 & 1577 & 1570 & 1566 & 1563 & 1559 & 1551\end{array}$

Fig 3 | Components of coprimary composite in patients with acute coronary syndrome with or without ST segment elevation. *Major and unrelated to coronary artery bypass graft

There was no heterogeneity of treatment effect on mortality according to qualifying acute coronary syndrome at baseline $(\mathrm{P}=0.73)$, with bivalirudin associated with fewer cases of all cause death $(0.68$, 0.46 to $1.01, \mathrm{P}=0.053)$ and cardiovascular death $(0.67$, 0.45 to $1.00, \mathrm{P}=0.048)$ compared with heparin in patients with ST segment elevation and directionally similar effect in patients without ST segment elevation $(0.77,0.41$ to $1.46, \mathrm{P}=0.43$, and $0.76,0.40$ to 1.47 , $\mathrm{P}=0.42$, respectively, table 2 , fig 3 , and supplementary figure $3 \mathrm{~A})$.
Bivalirudin was associated with lower rates of BARC 3 or 5 bleeding, both in patients with ST segment elevation (0.60, 0.39 to $0.92 ; \mathrm{P}=0.019)$ and in patients without $\mathrm{ST}$ segment elevation ( $0.47,0.26$ to 0.85 ; $\mathrm{P}=0.011)$ with similar treatment effect using the GUSTO (moderate or severe) and the TIMI (major or minor) classifications of bleeding (table 2, fig 3, and supplementary figure 3D and appendix).

Acute stent thrombosis (definite and definite or probable) were not statistically different between the groups with ST segment elevation (1.87, 0.83 to 4.20, $\mathrm{P}=0.13$, and $1.88,0.87$ to $4.06, \mathrm{P}=0.10$, respectively) and without 


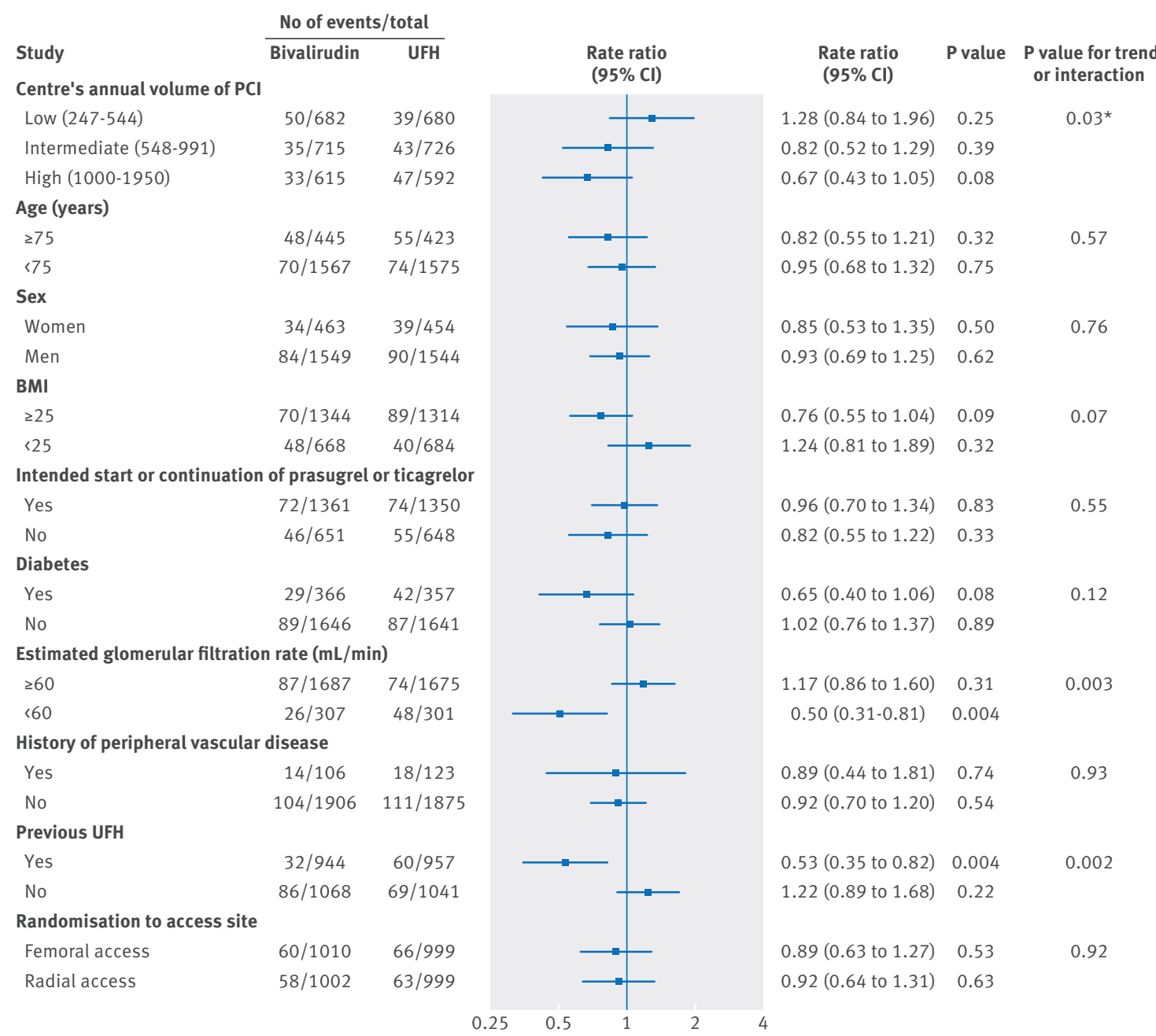

Fig 4 | Stratified analysis of coprimary composite of all cause mortality, myocardial infarction, or stroke in patients with acute coronary syndrome with ST segment elevation. UFH=unfractionated heparin; $\mathrm{PCl}=$ percutaneous coronary intervention; $\mathrm{BMI}=$ body mass index

ST segment elevation $(0.75,0.17$ to $3.37, \mathrm{P}=0.71$, and 0.50 , 0.13 to $2.01, \mathrm{P}=0.32$, respectively), with the $\mathrm{P}$ value for interaction with qualifying acute coronary syndrome of 0.29 for acute definite stent thrombosis and 0.09 for acute definite or probable stent thrombosis.

Rates of myocardial infarction were similar between bivalirudin and heparin in patients with and without ST segment elevation (1.24, 0.88 to 1.76 , and $0.95,0.78$ to 1.16 , respectively, $\mathrm{P}$ for interaction 0.19 ; fig 3). Notably, 30 day event rates differed markedly between the two populations: $3.3 \%$ in patients with ST segment elevation and $15 \%$ in those without ST segment elevation.

Randomised treatment effect on stroke was directionally opposite in patients with and without ST elevation (P for interaction 0.0052), with bivalirudin associated with a lower risk of stroke compared with heparin in patients with ST segment elevation (0.35, 0.13 to 0.97 , $\mathrm{P}=0.036)$ and a higher risk of stroke in patients without ST segment elevation (4.02, 0.85 to $18.95, \mathrm{P}=0.057$ ).

\section{Additional analyses}

Figures 4-7 list the randomised treatment effect on major adverse cardiovascular events and net adverse clinical events as well as all cause mortality and bleeding in patients with and without ST segment elevation according to prespecified subgroups (also see the supplementary appendix). In patients with ST segment elevation, the randomised treatment effect appeared consistent across most subgroups, with the exception of patients with an estimated glomerular filtration rate of less than $60 \mathrm{~mL} / \mathrm{min}$, with previous use of unfractionated heparin and treated in centres with a high volume of percutaneous coronary intervention, where the bivalirudin strategy appeared more effective and safe than the heparin strategy. In patients with an estimated glomerular filtration rate of less than $60 \mathrm{~mL} / \mathrm{min}$, bivalirudin appeared to be associated with a reduced risk of death and major bleeding. Treatment effects seemed consistent also in patients who qualified for the group without ST segment elevation, with a weak nominally significant interaction for intended or ongoing use of prasugrel or ticagrelor compared with clopidogrel.

\section{Discussion}

The main finding of this analysis-the largest randomised comparison of bivalirudin with heparin in 


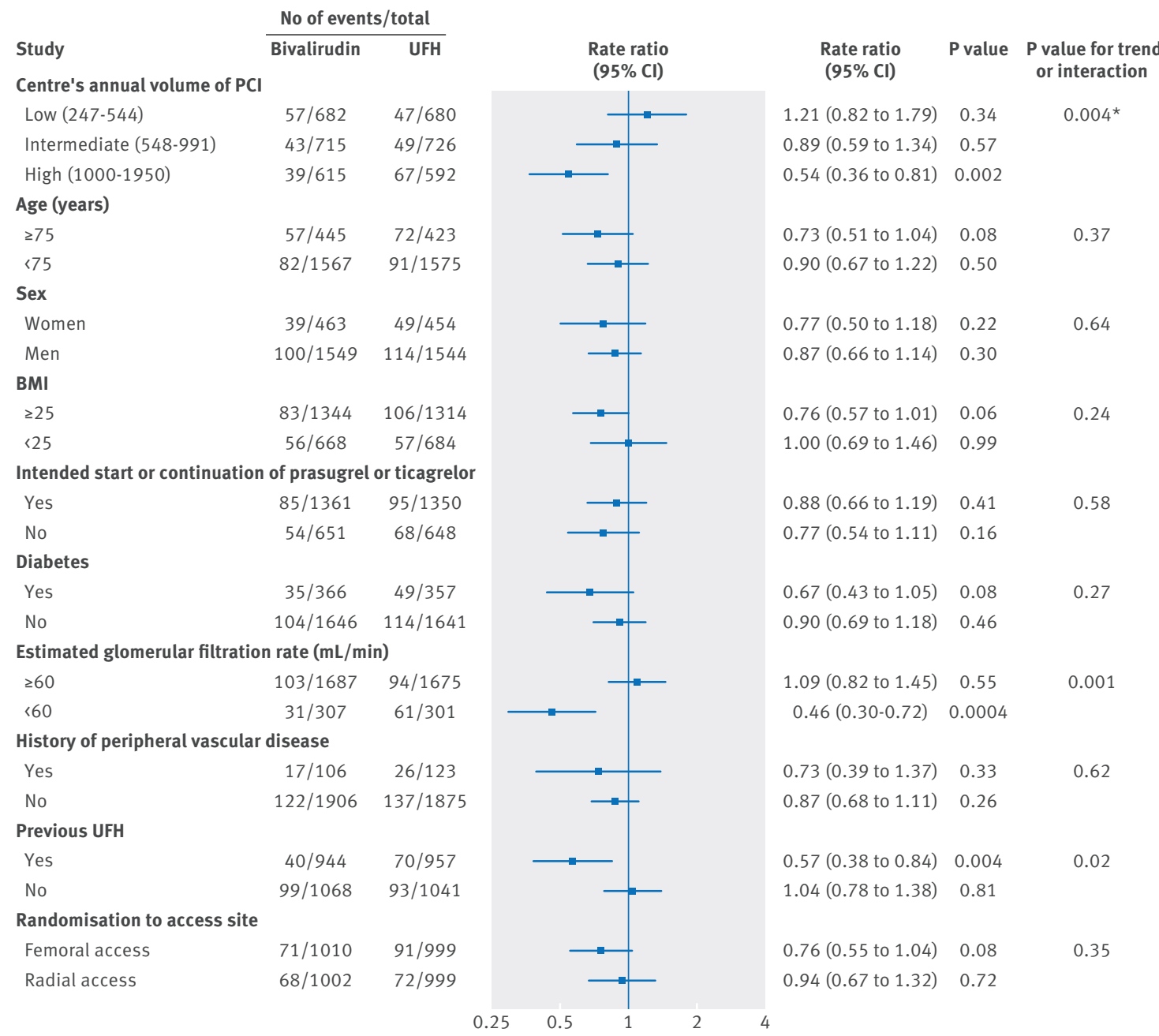

Fig 5 | Stratified analysis of coprimary composite of all cause mortality, myocardial infarction, stroke, or BARC type 3 or 5 bleeding (major and unrelated to coronary artery bypass graft) in patients with acute coronary syndrome with ST segment elevation. $\mathrm{UFH}=$ unfractionated heparin; $\mathrm{PCl}=$ percutaneous coronary intervention; $\mathrm{BMI}=$ body mass index

patients with acute coronary syndrome with ST segment elevation and one of the largest in patients with acute coronary syndrome without ST segment elevation treated with modern antiplatelet agents-is that a regimen of bivalirudin monotherapy, compared with unfractionated heparin with provisional glycoprotein IIb/IIIa inhibitors, did not result in reduced major adverse cardiovascular events or net adverse clinical events. These results are consistent with the findings from the overall population with acute coronary syndrome. ${ }^{6}$

\section{Efficacy and safety of bivalirudin versus heparin strategies according to type of acute coronary syndrome}

A strategy of bivalirudin monotherapy was associated with reduced bleeding compared with heparin with provisional use of glycoprotein IIb/IIIa inhibitors. . $^{2-48}$ This reduction in bleeding was consistent across bleeding classifications (including fatal events), not clearly related to randomised access site (which was allocated in MATRIX), and of similar magnitude in patients with acute coronary syndrome with and without ST segment elevation. These observations suggest that bivalirudin, if intended as a strategy to minimise bleeding, may be complementary to other strategies (eg, radial access) and could be applied with few restrictions to the general population with acute coronary syndrome, as also suggested by the association of bivalirudin with a reduction in death and bleeding in patients with a low estimated glomerular filtration rate. In secondary analyses we observed that bivalirudin was associated with a reduction in all cause mortality as a result of lower cardiovascular disease mortality, a difference that in this analysis was similar between patients with and without ST segment elevation (P for interaction 0.72).

The excess risk of acute stent thrombosis associated with bivalirudin is well documented. ${ }^{238}$ We did not observe significant differences in the rate of acute stent thrombosis between randomised strategies in the patients with and without ST segment elevation. While the risk of acute stent thrombosis with bivalirudin in patients with ST segment elevation has been well documented (and is directionally similar in MATRIX), we observed no increased risk in patients without ST 


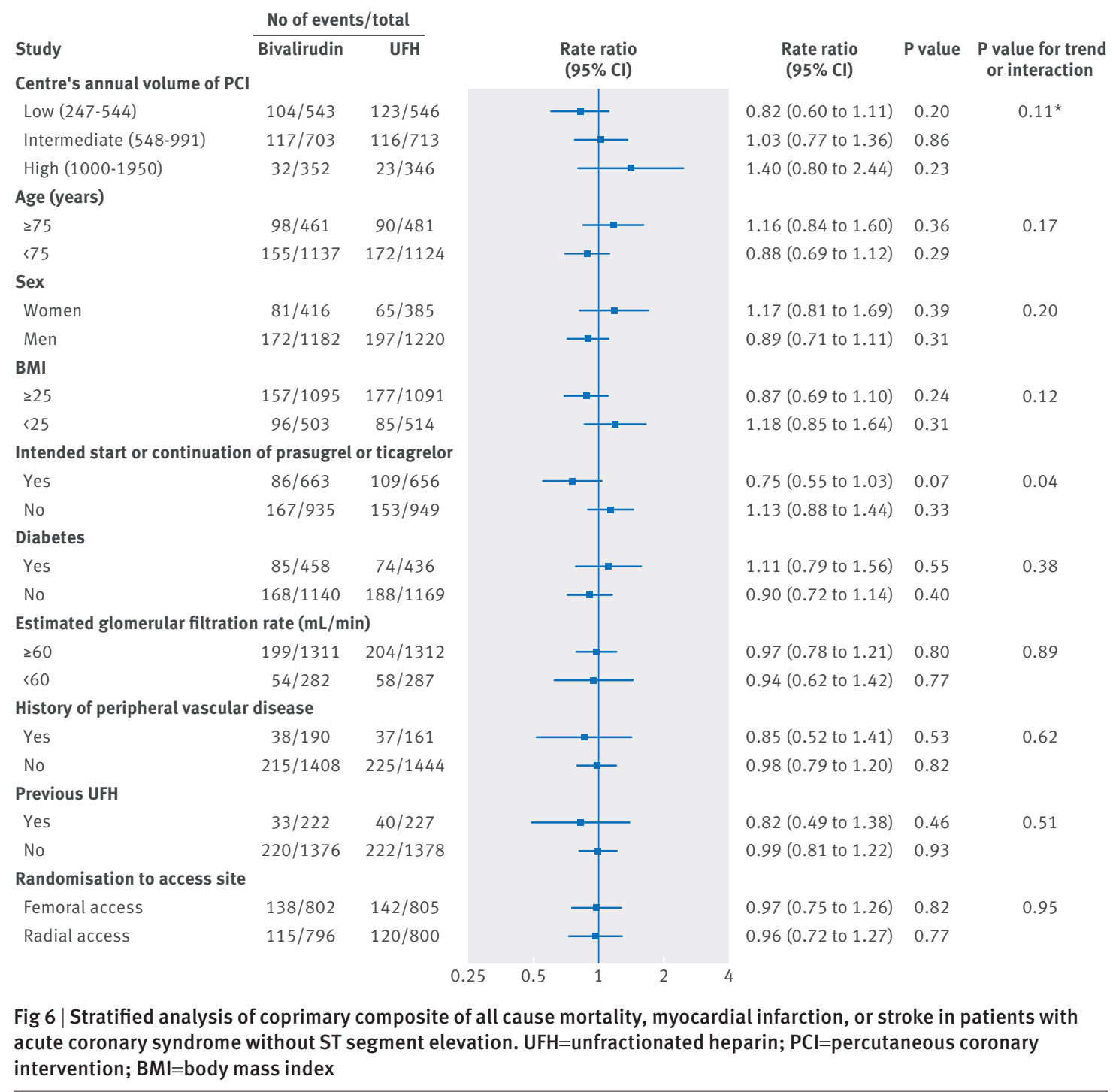

segment elevation, especially if treated with potent $\mathrm{P}_{2} \mathrm{Y}_{12}$ inhibitors.

There was no clear effect of randomised treatment on myocardial infarction according to qualifying acute coronary syndrome. The myocardial infarction component was far more common ( $>4$ times) in patients without ST segment elevation compared with patients with ST segment elevation, reflecting the contribution of procedural related myocardial infarction events in patients without ST segment elevation and a planned percutaneous coronary intervention. So, even when procedural myocardial infarctions are not accounted for (ie, patients with ST segment elevation), a strategy of bivalirudin monotherapy did not have a measurable effect on either coprimary endpoints, indicating a complex, competitive balance between thrombosis and bleeding, which may explain the overall neutral results. Unexpectedly, a nominally significant interaction effect between randomised antithrombotic strategies compared with qualifying acute coronary syndrome on stroke was detected. No such effect has previously been reported, and since it currently defies, to our knowledge, any plausible biological explanation, we concur it might represent a spurious finding.
Finally, subgroup analysis indicates that a strategy of bivalirudin monotherapy with glycoprotein IIb/IIIa inhibitors restricted to angiographic complications might be useful in patients with ST segment elevation pretreated with heparin and with renal dysfunction. A benefit of bivalirudin in patients who have received heparin has been consistently reported. ${ }^{14-16}$ This effect, perhaps related to an insufficient level of anticoagulation provided by bivalirudin alone, suggests that the common practice of an immediate heparin bolus in patients with ST segment elevation followed by bivalirudin seems to be safe. The effect of bivalirudin in patients with renal dysfunction is less consistent, ${ }^{17} 18$ but suggests that in the acute setting (where data on renal function are often not available) bivalirudin has a favourable safety profile. Finally, a benefit of bivalirudin compared with a heparin strategy in patients without ST segment elevation (but not with ST segment elevation) treated with novel $\mathrm{P}_{2} \mathrm{Y}_{12}$ inhibitors might reflect a longer time required for these agents to reach their desired effect, a possible consideration for the selection of an antithrombotic regimen in this population. ${ }^{19}$ 


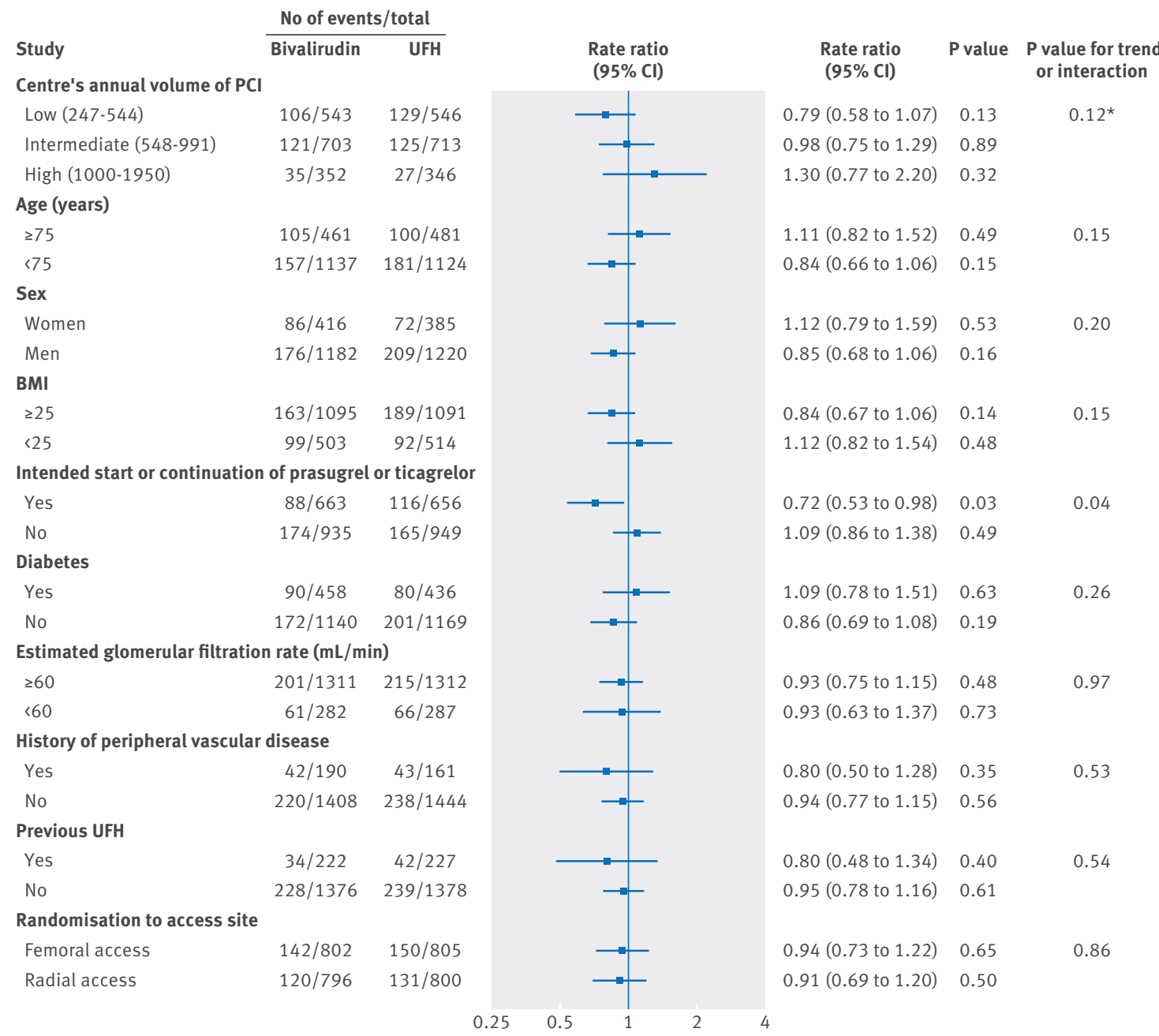

Fig $7 \mid$ All cause mortality, myocardial infarction, stroke, or BARC type 3 or 5 bleeding (major and unrelated to coronary artery bypass graft) in patients with acute coronary syndrome without ST segment elevation. UFH=unfractionated heparin; $\mathrm{PCl}=$ percutaneous coronary intervention; $\mathrm{BMI}=$ body mass index

\section{Limitations of this study}

We acknowledge some limitations in the current analysis. Although the reported subgroups were prespecified in the protocol, and separate statistical analyses on these subgroups were planned, we did not adjust for multiple comparisons, increasing the risk of type 1 errors. Also, the results for the coprimary endpoints were all negative. Therefore, differential effects across subgroups of the randomised treatments, if any, must be considered hypothesis generating. Also, the study was not powered for type of acute coronary syndrome at baseline. Accordingly, our ability to detect smaller treatment differences was limited. Finally, the study compared two antithrombotic strategies (with the heparin arm intended to reflect use of glycoprotein IIb/IIIa inhibitors in clinical practice) rather than two drugs. The different use of glycoprotein IIb/IIIa inhibitors in the two study arms has thus challenged our ability to understand the efficacy and safety of the anticoagulants drugs alone.

\section{Conclusions}

A strategy of bivalirudin monotherapy compared with heparin with or without glycoprotein IIb/IIIa inhibitors did not result in reduced major adverse cardiovascular events or net adverse clinical events in patients with acute coronary syndrome with or without ST segment elevation. The choice of the anticoagulant regimen thus requires a careful balance between the expected risk of bleeding and thrombotic complications with the expected benefits for each patient. Further research is needed to better understand optimal patients, settings, and combinations of antithrombotic treatments, particularly in those with a high risk of early thrombotic complications or a high risk of bleeding, or both.

\section{AUTHOR AFFILIATIONS}

${ }^{1}$ Fondazione IRCCS Policlinico San Matteo, Pavia, Italy EUSTRATEGY Association, Forli', Italy

\section{${ }^{3}$ CTU Bern, University of Bern, Switzerland}

${ }^{4}$ Institute of Social and Preventive Medicine (ISPM), University of Bern, Switzerland

${ }^{5}$ Policlinico Multimedica IRCSS, University of Milan, Milan, Italy ${ }^{6}$ Division of Cardiology, Department of Cardiothoracic Sciences, Second University of Naples, Naples, Italy

7Department of Cardiology, ASL3 Ospedale Villa Scassi, Genoa, Italy ${ }^{8}$ Clinica Mediterranea, Napoli, Italy

${ }^{9}$ Ospedale Fatebene Fratelli, Milano, Italy

10University Hospital Maggiore della Carità, Novara, Italy 
${ }^{11}$ Ospedale Sirai-Carbonia, Carbonia, Italy

${ }^{12}$ Humanitas Research Hospital, IRCCS, Rozzano, Italy

${ }^{13}$ Division of Cardiology-Department of Advanced Biomedical

Sciences, Federico II University of Naples

${ }^{14} \mathrm{~A} O \mathrm{O}$ Ospedale di Desio, Lombardia, Italy

${ }^{15}$ IRCCS San Martino-IST, Genoa, Italy

${ }^{16}$ Interventional Cardiology Sandro Pertini Hospital Rome, Italy

${ }^{17}$ Ospedale Pasquinucci, Massa, Italy

${ }^{18}$ Citta' di Lecce Hospital, Lecce, Italy

${ }^{19}$ Ospedale Giovanni Paolo II, Sciacca, Italy

${ }^{20}$ Università degli Studi G d'Annunzio Chieti e Pescara, Chieti, Italy

${ }^{21}$ Ospedale San Jacopo, Pistoia, Italy

${ }^{22}$ Azienda Ospedali Riuniti-Presidio GM Lancisi, Ancona, Italy

${ }^{23}$ Ospedale San Raffaele IRCCS, Milano, Italy

${ }^{24}$ Hospital Clinic, Cardiovascular Institute, IDIBAPS, Barcelona, Spain

${ }^{25}$ AORN Cardarelli, Napoli, Italy

${ }^{26}$ Erasmus MC, Rotterdam, Netherlands

${ }^{27}$ Applied Health Research Centre, Li Ka Shing Knowledge Institute of St Michael's Hospital, and Department of Medicine, University of Toronto, Canada

${ }^{28}$ Swiss Cardiovascular Centre Bern, Bern University Hospital, CH-3010 Bern, Switzerland

We thank the MATRIX patients and investigators who volunteered to help others.

Contributors: SL wrote the first draft of the manuscript and subsequent revision, and interpreted it in collaboration with the othe authors. SL, EF, PC, PB, CB, MF, BC, AL, SI, DZ-P, GE, ST, AZ, SR CP, AL, $F A, M Z, M C, G G, A C, S B, C M, N M v M, S W$, and MV acquired data. MR, $E N, D H$, and PJ performed the analysis and interpreted it in collaboration with the other authors. MV conceived and designed the study and obtained funding. SL and MV had full access to the final data and had final responsibility for the content of the report and the decision to submit for publication. All authors critically revised the paper for important intellectual content and approved the final version. SL and MV are the guarantors.

Funding: The MATRIX programme was sponsored by the Italian Society of Invasive Cardiology (GISE), a non-profit organisation, and received grant support from The Medicines Company and TERUMO. The Medicines Company provided bivalirudin for the study. The sponsor had no role in study design, data collection, data monitoring, analysis, interpretation, or writing of the report.

Competing interests: All authors have completed the ICMJE uniform disclosure form at www.icmie.org/coi disclosure.pdf and declare no support from any organisation for the submitted work. They declare the following financial relations: SL reports honorariums for advisory boards from The Medicines Company during the conduct of the study outside the submitted work; MF received honorariums for advisory boards or as speaker at scientific congresses or as consultant from Astra Zeneca, Eli Lilly, and the Medicines Company, outside the submitted work; BC reports lecture fees from Abbott, AB Medica, Hexacath, Astra, Movi, and Concept Medicals and research grants from AB Medica, Aachen Resonance, and Movi, all outside the submitted work; MZ received honorariums as speaker at scientific congresses from Astra Zeneca and Pfizer, outside the submitted work; SR reports personal fees for advisory board participation from AstraZeneca; PJ has received research grants to the institution from Astra Zeneca, Biotronik, Biosensors International, Eli Lilly, and the Medicines Company, and serves as unpaid member of the steering group of trials funded by Astra Zeneca, Biotronik, Biosensors, St Jude Medical, and the Medicines Company; MV reports grants from the Medicines Company and Terumo during the conduct of the study. No other relationships or activities that could appear to have influenced the submitted work are reported.

Ethical approval: This study was approved by the ethics committee from each participating site.

Data sharing: No additional data available.

Transparency: The manuscript's guarantors (SL and MV) affirm that the manuscript is an honest, accurate, and transparent account of the study being reported; that no important aspects of the study have been omitted; and that any discrepancies from the study as planned have been explained.

This is an Open Access article distributed in accordance with the Creative Commons Attribution Non Commercial (CC BY-NC 3.0) license, which permits others to distribute, remix, adapt, build upon this work non-commercially, and license their derivative works on different terms, provided the original work is properly cited and the use is non-

commercial. See: http://creativecommons.org/licenses/by-nc/3.0/.

1 Shahzad A, Kemp I, Mars C, et al. HEAT-PPCI trial investigators. Unfractionated heparin versus bivalirudin in primary percutaneous coronary intervention (HEAT-PPCI): an open-label, single centre, randomised controlled trial. Lancet 2014;384:1849-58. doi:10.1016/S0140-6736(14)60924-7.

2 Stone GW, Witzenbichler B, Guagliumi G, et al. HORIZONS-AMI Trial Investigators. Bivalirudin during primary $\mathrm{PCl}$ in acute myocardial infarction. NEngl / Med 2008:358:2218-30. doi:10.1056/NEIMoa0708191.

3 Kastrati A, Neumann FJ, Schulz S, et al. ISAR-REACT 4 Trial Investigators. Abciximab and heparin versus bivalirudin for non-ST-elevation myocardial infarction. N Engl/ Med 2011:365:1980-9. doi:10.1056/NEIMoa1109596.

4 Stone GW, McLaurin BT, Cox DA, et al. ACUITY Investigators. Bivalirudin for patients with acute coronary syndromes. N Engl J Med 2006;355:2203-16. doi:10.1056/NEJMoa062437.

5 Valgimigli M. MATRIX investigators. Design and rationale for the Minimizing Adverse haemorrhagic events by TRansradial access site and systemic Implementation of angioX program. Am Heart J 2014;168:838-45.e6. doi:10.1016/i.ahi.2014.08.013.

6 Valgimigli M, Frigoli E, Leonardi S, et al. MATRIX Investigators. Bivalirudin or Unfractionated Heparin in Acute Coronary Syndromes. N Engl J Med 2015;373:997-1009. doi:10.1056/NEJMoa1507854.

7 De Luca L, Leonardi S, Cavallini C, et al. EYESHOT Investigators. Contemporary antithrombotic strategies in patients with acute coronary syndrome admitted to cardiac care units in Italy: The EYESHOT Study. Eur Heart J Acute Cardiovasc Care 2015;4:441-52. doi:10.1177/2048872614560505

8 Cavender MA, Sabatine MS. Bivalirudin versus heparin in patients planned for percutaneous coronary intervention: a meta-analysis of randomised controlled trials. Lancet 2014:384:599-606. doi:10.1016/ S0140-6736(14)61216-2.

9 Valgimigli M, Gagnor A, Calabró P, et al. MATRIX Investigators. Radial versus femoral access in patients with acute coronary syndromes undergoing invasive management: a randomised multicentre trial. Lancet 2015;385:2465-76. doi:10.1016/S0140-6736(15)60292-6.

10 Nikus K, Pahlm O, Wagner G, et al. Electrocardiographic classification of acute coronary syndromes: a review by a committee of the International Society for Holter and Non-Invasive Electrocardiology. J Electrocardiol 2010;43:91-103. doi:10.1016/.j.electrocard.2009.07.009.

11 Mehran R, Rao SV, Bhatt DL, et al. Standardized bleeding definitions for cardiovascular clinical trials: a consensus report from the Bleeding Academic Research Consortium. Circulation 2011;123:2736-47. doi:10.1161/CIRCULATIONAHA.110.009449.

12 GUSTO Investigators. An international randomized trial comparing four thrombolytic strategies for acute myocardial infarction. The GUSTO investigators. N Engl / Med 1993;329:673-82. doi:10.1056 NEIM199309023291001.

13 Clayton D, Hills M. Statistical models in epidemiology. Oxford University Press, 1993.

14 Dangas GD, Mehran R, Nikolsky E, et al. HORIZONS-AMI Trial Investigators. Effect of switching antithrombin agents for primary angioplasty in acute myocardial infarction: the HORIZONS-SWITCH analysis. J Am Coll Cardiol 2011;57:2309-16. doi:10.1016/j. jacc.2011.01.038.

15 Koutouzis M, Lagerqvist B, James S, et al. Unfractionated heparin administration in patients treated with bivalirudin during primary percutaneous coronary intervention is associated lower mortality and target lesion thrombosis: a report from the Swedish Coronary Angiography and Angioplasty Registry (SCAAR). Heart 2011;97:14848. doi:10.1136/hrt.2011.224709.

16 White HD, Chew DP, Hoekstra JW, et al. Safety and efficacy of switching from either unfractionated heparin or enoxaparin to bivalirudin in patients with non-ST-segment elevation acute coronary syndromes managed with an invasive strategy: results from the ACUITY (Acute Catheterization and Urgent Intervention Triage strategY) trial. J Am Coll Cardiol 2008;51:1734-41. doi:10.1016/j.jacc.2007.12.052.

17 Saltzman Al, Stone GW, Claessen BE, et al. Long-term impact of chronic kidney disease in patients with ST-segment elevation myocardial infarction treated with primary percutaneous coronary intervention: the HORIZONS-AMI (Harmonizing Outcomes With Revascularization and Stents in Acute Myocardial Infarction) trial. JACC Cardiovasc Interv 2011;4:1011-9. doi:10.1016/j.jcin.2011.06.012.

18 Chew DP, Bhatt DL, Kimball W, et al. Bivalirudin provides increasing benefit with decreasing renal function: a meta-analysis of randomized trials. Am / Cardio 2003:92:919-23. doi:10.1016/ S0002-9149(03)00970-6.

19 Franchi F, Angiolillo DJ. Novel antiplatelet agents in acute coronary syndrome. Nat Rev Cardiol 2015;12:30-47. doi:10.1038/ nrcardio.2014.156

(c) BMJ Publishing Group Ltd 2016

Supplementary appendix: additional material 